\title{
Pneumococcal vaccine and HIV infection: report of a vaccine failure and reappraisal of its value in clinical practice
}

\author{
L J Willocks, K Vithayathil, A Tang, A Noone
}

\begin{abstract}
A clinical failure of pneumococcal vaccine is reported. A 22 year old African woman was given 23-valent pneumococcal vaccine at her initial presentation with HIV infection. She was asymptomatic and had a CD4 + lymphocyte count above 500 cells $/ \mathrm{mm}^{3}$. Eighteen months later she died of meningitis and septicaemia due to Streptococcus pneumoniae type 9 (an antigen included in the 23valent vaccine). Pneumococcal antibody levels performed on stored blood demonstrated no serological response to the vaccine. This is the first reported case of clinical failure of pneumococcal vaccine in an HIV infected patient who received vaccine whilst at the asymptomatic stage of HIV infection and with relatively intact immune function. The literature pertaining to pneumococcal vaccination in the context of HIV infection was reviewed. Pneumococcal vaccination is recommended for HIV positive patients in the UK by the Departments of Health. It is likely that many physicians are not aware of these recommendations or are concerned about the poor efficacy of the vaccine, and it may consequently be underused in clinical practice. But the potential gain to the HIV positive patient is such that the vaccine should be offered to all HIV positive patients as soon as they present for medical care, irrespective of the stage of HIV disease. Physicians and patients should be aware that the vaccine is not fully protective and that episodes of sepsis, pneumonia and meningitis could still be pneumococcal in origin and should be treated appropriately. Awareness of the substantial risks of pneumococcal disease in HIV infected patients with prompt diagnosis and effective treatment is the most important strategy to decrease morbidity and mortality.
\end{abstract}

(Genitourin Med 1995;71:71-72)

Keywords: pneumococcal vaccine; HIV

\section{Introduction}

The incidence of pneumococcal disease in HIV infected patients has been calculated at up to 30 times that of the general population and is particularly high in HIV positive drug users, African and AIDS patients. ${ }^{1-5}$ The most common presentation is with pneumococcal community acquired pneumonia which is more likely to be bacteraemic, recurrent and fatal in HIV infected patients. ${ }^{3-7}$

The UK Departments of Health recommend that "pneumococcal vaccine should be considered for all those aged over two years ... with immunodeficiency ... including HIV infection at all stages" ${ }^{8}$ From US data, immunisation has been under-utilised in clinical practice, perhaps because of the literature emphasis on lack of serological response to vaccine. ${ }^{59-12}$ The extent of use of pneumococcal vaccine in the context of HIV infection in the UK is not known.

The prevention of pneumococcal disease is now even more vital with the world wide spread of penicillin resistant pneumococci. ${ }^{413-15}$ We report a clinical failure of pneumococcal vaccine in a patient who received pneumococcal vaccination when at an early stage of HIV infection.

\section{Case report}

A 22 year old African woman was diagnosed HIV positive at a genitourinary medicine clinic. She had in the past had a left salpingooophorectomy and appendicectomy in Africa and gave a history of blood transfusion 10 years previously. On her initial visit she was found to have positive syphilis serology (VDRL-, TPHA +, FTA +) and was given a course of procaine penicillin injections. She was also given 23 -valent pneumococcal vaccine $0.5 \mathrm{ml}$ intramuscularly.

At follow-up visits she remained well although was admitted on one occasion with malaria following a visit to Africa. Her CD4+ lymphocyte count was persistently above 500 cells $/ \mathrm{mm}^{3}$ and she was not receiving any prophylaxis.

Eighteen months after her initial HIV diagnosis and pneumococcal vaccination she attended for routine repeat syphilis serology. She was asymptomatic and had a normal neurological assessment. That same night she felt unwell and was admitted to hospital 60 hours later, moribund and with a fever of $40^{\circ} \mathrm{C}$. She died shortly after admission. Streptococcus pneumoniae type 9 (an antigen included in the 23-valent vaccine) was subsequently grown from her CSF and blood. Pneumococcal antibody levels were assayed on stored sera. The pre vaccination antibody level was 15 units $/ \mathrm{ml}$ and this fell to 9 units $/ \mathrm{ml} 10$ months after vaccination. The normal level in unimmun-ised adults is above 20 units $/ \mathrm{ml}$ and at least a two fold rise in levels would be expected after vaccination (Helen Griffiths, personal communication).$^{16}$ 


\section{Discussion}

This is at least the sixth reported case of pneumococcal vaccine failure in a patient with HIV infection and without other risk factors, and is the second reported case from the UK. Of the previous five cases, full details are not available on two, ${ }^{1718}$ two patients had AIDS or $\mathrm{ARC}^{619}$ and the UK patient was vaccinated when he was already antigenaemic and his CD4+ lymphocyte count was below 200 cells $/ \mathrm{mm}^{3} .{ }^{20}$ This is the first reported case of clinical failure in a patient who received vaccine with relatively intact immune function (CD4+ lymphocyte count above 500 cells $/ \mathrm{mm}^{3}$ ) and who was at the "asymptomatic" stage of HIV infection.

The pneumococcal serotypes causing disease in HIV positive patients are the same as in any other group of patients from that geographical area ${ }^{21}$ and $80-100 \%$ of bacteraemic isolates from HIV positive patients are included in the 23-valent vaccine. ${ }^{17}$ So any clinical failure is most likely to be due to poor response to the vaccine. ${ }^{17}$

HIV infected patients often have low baseline antibody titres to many pneumococcal serotypes and impaired antibody responses after immunisation. ${ }^{9-12}$ A poorer antibody response has been correlated with declining $T$-cell function and more advanced clinical disease. ${ }^{22}$ But despite lower levels of antibody responses, many HIV positive patients are able to mount adequate titres to one or more type-specific antibodies. ${ }^{23}$ There is no clear correlation between antibody levels and clinical response to vaccination but assessment of antibody responses to pneumococcal vaccine may be useful. Although the present data show no convincing evidence of efficacy, and the extent of vaccine use in the UK clinical practice is not known, it is not ethically possible to conduct a study on clinical efficacy since vaccination is already recommended by the UK Departments of Health. ${ }^{6}$

Although the efficacy of pneumococcal vaccine may be lower in HIV infected patients the potential benefit is great because of the high rate of disease. ${ }^{21}$ The cost-effectiveness of pneumococcal vaccine was elegantly demonstrated by Rose using a hypothetical cohort of 30 year old patients at different stages of infection. ${ }^{24}$ For a cohort of patients with a CD4 + lymphocyte count of 650 cells $/ \mathrm{mm}^{3}$, 17 vaccinations must be administered to prevent one admission for pneumococcal infection and 94 to prevent one death. For a cohort with less than $350 \mathrm{CD} 4+$ lymphocyte cells $/ \mathrm{mm}^{3}$, between 18 and 368 vaccinations must be administered to prevent one hospitalisation and 104 to 1,842 to prevent one death. The authors concluded that even under the worst case assumptions the vaccination saves money over the lifetime of the cohort because relatively few vaccinations must be given to prevent a hospitalisation or death.

One caveat in the use of pneumococcal vaccine is that physicians and patients should be aware that pneumococcal vaccination is not fully protective and that any episodes of sepsis, pneumonia or meningitis could still be pneumococcal in origin and should be treated appropriately. Awareness of the substantial risks of pneumococcal disease in HIV infected patients with prompt diagnosis and effective treatment is the most important strategy to decrease mortality. ${ }^{25}$ Additionally, pneumococcal vaccine should be offered to all HIV positive patients as soon as they present for medical care, irrespective of the stage of HIV disease.

We thank Helen Griffiths for determining the pneumococcal antibody levels.

1 Schuchat A, Broome V, Hightower A, Costa SJ, Parkin W. Use of surveillance for invasive pneumococcal disease to estimate the size of the immunosuppressed HIV-infected population. $\mathscr{F} A M A$ 1991;265:3275-9.

2 Selwyn PA, Feingold AR, Hartel D, et al. Increased risk of bacterial pneumonia in HIV-infected intravenous drug users without AIDS. AIDS 1988;2:267-72.

3 Gilks CF, Brindle RJ, Otieno LS, et al. Life-threatening bacteraemia in HIV-1 seropositive adults admitted to hospital in Nairobi, Kenya. Lancet 1990;336:545-8

4 Garcia-Leoni ME, Moreno S, Rodeno P, Cercenado E, Vicente T, Bouza E. Pneumococcal pneumonia in adult hospitalised patients infected with the human immunodeficiency virus. Arch Int Med 1992;152:1808-12.

5 Caiaffa WT, Graham NMH, Vlahov D. Bacterial pneumonia in adult populations with human immunodeficiency virus (HIV) infection. Am $\mathcal{f}$ Epidemiol 1993;138:909-22.

6 Simberkoff MS, El Sadr W, Schiffman G, Rahal JJ. Streptococcus pneumoniae infections and bacteraemia in patients with AIDS, with report of a pneumococcal vaccine failure. Am Rev Respir Dis 1984;130:1174-6.

7 Polsky B, Gold JWM, Whimbey E, et al. Bacterial pneumonia in patients with AIDS. Ann Int Med 1986; 104:38-41.

8 UK Departments of Health. Immunisation Against Infectious Disease 1992. HMSO, London 1992, pps $100-3$

9 Klein RS, Selwyn PA, Maude D, Pollard C, Freeman K, Schiffman G. Response to pneumococcal vaccine among asymptomatic heterosexual partners of persons with AIDS and intravenous drug users infected with HIV. $\mathcal{F}$ Infect Dis 1989;160:826-31.

10 Ammann AJ, Schiffman G, Abrams D, Volberding P, Ziegler J, Conant M. B-cell immunodeficiency in AIDS. $\mathcal{f A M} A$ 1984;251:1447-9.

11 Unsworth DJ, Rowen D, Carne C, Sonnex C, Baglin T, Brown DL. Defective IgG2 response to Pneumovax in HIV seropositive patients. Genitourin Med 1993;69: 373-6.

12 Hopewell PC. Prevention of lung infections associated with HIV infection. In: AIDS and the lung. Thorax 1989;44:1038-44.

13 Gellert G, Bock BV, Meyers H, Robertson C, Ehling LR. Penicillin-resistant pneumococcal meningitis in an HIVPenicillin-resistant pneumococcal meningitis in

14 Blumberg HM, Rimland D. Nosocomial infection with penicillin-resistant pneumococci in patients with AIDS. Infect Dis 1989;160:725-6.

15 Istorico LJ, Bradsher RW, Abernathy RS, Vannier A, Martin RE. Community-acquired pneumonia with penicillin-resistant pneumococci in a patient with AIDS. f Acq Immune Defic Syndr 1991;4:1164.

16 Kroon FP, van Dissel JT, de Jong JC, van Furth R. Antibody response to influenza, tetanus and pneumococcal vaccines in HIV-seropositive individuals in relation to the number of CD4+ lymphocytes. AIDS 1994;8:469-76.

17 Janoff EN, O'Brien J, Thompson P, et al. Streptococcus pneumoniae colonization, bacteraemia and immune response among persons with human immunodeficiency virus infection. 7 Infect Dis 1993;167:49-56.

18 Yamaguchi $E$, Charache $P$, Chaisson RE. Increasing incidence of pneumococcal infections associated with HIV infection in an inner city hospital, 1985-9. Am Rev Respir Dis 1990;141:A619.

19 Witt DJ, Craven DE, McCabe WR. Bacterial infections in adult patients with AIDS and ARC. Am $\mathcal{Y}$ Med 1987;82: $900-6$.

20 Flegg PJ, Brettle RP, Bell JE, Bird AG, Busuttil A. Fatal pneumococcal meningitis in an HIV-infected drug user despite previous pneumococcal immunization. Int STD AIDS 1994;5:221-2.

21 Redd SC, Rutherford GW, Sande MA, et al. The role of human immunodeficiency virus infection in pneumococcal bacteraemia in San Francisco residents. $\mathcal{F}$ Infect Dis 1990;162:1012-7.

22 Rodriguez-Barradas MC, Musher DM, Lahart C, et al. Antibody to capsular polysaccharides of Streptococcus Antibody to capsular polysaccharides of Streptococcus
pneumoniae after vaccination of HIV-infected subjects pneumoniae after vaccination of HIV-infected subjects
with 23-valent pneumococcal vaccine. $\mathcal{F}$ Infect Dis 1992; with 23-valer.

23 Huang KL, Ruben FL, Rinaldo CR, Kingsley L, Lyter DW, Ho $M$. Antibody responses after influenza and pneumococcal immunization in HIV-infected homosexual men. $\mathscr{f} A M A$ 1987;257:2047-50

24 Rose DN, Schechter CB, Sacks HS. Influenza and pneumococcal vaccination of HIV-infected patients: a policy analysis. $A m \mathcal{F}$ Med 1993;94:160-8.

25 Krumholz HM, Sande MA, Lo B. Community-acquired bacteraemia in patients with AIDS: clinical presentation bacteriology and outcome. Am f Med 1989;86:776-9. 